\title{
Análisis de noticias falsas generadas y transmitidas a partir de los avances tecnológicos digitales desde una perspectiva de diseño gráfico durante la fase inicial de la pandemia de covid-19
}




\section{Universidad Iberoamericana}

\section{Rodrigo Álvarez de Mattos}

mleplec@gmail.com

Profesor-TSU en Producción Gráfica

Es doctor en Imagen, Arte, Cultura y Sociedad (IMACS) por parte de la Facultad de Diseño (FD) de la Universidad Autónoma del Estado de Morelos (UAEM). También cuenta con la maestría en mercadotecnia por parte de la Escola Superior de Propaganda e Marketing (ESPM) de São Paulo, Brasil; y es egresado de la licenciatura de Diseño Gráfico de la Universidad Iberoamericana (UIA). De 2004 a 2012 se desempeñó a nivel nacional e internacional como diseñador editorial en medios de comunicación como el periódico Reforma, el grupo Expansión, el diario The Newsy Folhade São Paulo.

Prácticamente desde el inicio de la carrera Técnico Superior Universitario en Producción Cráfica (TSUPC) de la UIA ha colaborado como profesory continúa impartiendo múltiples asignaturas. 


\section{Resumen}

El comienzo de la pandemia por el covid-19 se ha caracterizado por un vertiginoso tránsito de informaciones que aparentan ser verdaderas, pero en realidad no lo son; $y$ esto en lugar de aliviar este mal lo agrava junto con otros padecimientos. Este artículo describe y analiza ciertos ejemplos de noticias falsas como parte de la dinámica actual de la Sociedad de la Información cuya intención es desinformar.

Palabras clave: covid-19; sociedad de la Información; diseño gráfico; avances tecnológicos digitales; internet; noticias falsas

\section{Abstract}

The beginning of the covid-19 pandemics has been characterized by a dizzying flow of information that appears to be true but in reality not. This, instead of healing this evil aggravates it as well as other conditions. This article describes and analyzes certain examples of fake news as part of the current dynamics of the Information Society whose intention is to misinform.

Keywords: covid-19; Information Society; Graphic Design; Digital Technological Advances; Internet; Fake News 


\section{Introducción}

$\mathbf{T}$

omando en consideración que la sociedad actual presenta múltiples padecimientos, este artículo se enfoca en el estudio de dos de ellos: la pandemia de covid-19y la desinformación. El primero se manifiesta en la salud pública y el segundo en el comportamiento social; y ambos representan un panorama complejo para el futuro próximo de la humanidad. Por tal motivo, a lo largo de cuatro secciones que componen este documento, se considerará la relación que vincula al diseño, sobre todo el gráfico, con los avances tecnológicos y la manera como inciden en la Sociedad de la Información.

En la primera sección se muestra el escenario de la pandemia de covid-19, iniciando con la definición realizada por la Organización Mundial de la Salud (OMS) y continuando con una breve descripción del contagio y transmisión de la enfermedad. Posteriormente se relatan situaciones particulares relacionadas con su reciente descubrimiento, para concluir con el análisis del impacto de la pandemia, haciendo énfasis en el contexto mexicano. Para este propósito fueron retomados ejemplos específicos que son ilustrados por los comunicados oficiales y los que, en contraparte, se produjeron con la intención de desprestigiarlos.

En la segunda sección se ejemplifica la relación existente entre el diseño y la Sociedad de la Información. De igual manera se explica la importancia de los datos como materia prima para generar información, y cómo estudiarlos. Enseguida se presenta la argumentación de la uniformización y la globalización como factores determinantes de la conceptualización de este tipo de sociedad expuesta por Armand Mattelart. Además, se expone la participación de los medios de comunicación convencionales.
Más adelante se hace referencia a la transición que permite la participación de nuevos colaboradores en la producción y transmisión de la información denominados receptores-emisores. En su conjunto, todos ellos comparten la intencionalidad de informar o "dar forma" a la sociedad. La creación de imágenes y la fijación de la información, actividades inicialmente propias del diseño son compartidas por una mayor cantidad de participantes. Esta situación combinada con la utilización de dispositivos digitales permite la rápida e inmediata transmisión de datos que al no ser contextualizados adecuadamente provocan desinformación.

La tercera sección dilucida ciertos casos que apoyan la relación entre el diseño y los avances tecnológicos, sobre todo los digitales. Este vínculo ha estado presente desde antes de la pandemia. Un ejemplo de esto es el modelo del arquitecto Rovalo compuesto por tres esquemas siendo uno de ellos el tecnológico (Rodríguez, 1995). Ante la intensidad del ritmo de producción y transmisión de la información, se cuestiona la posibilidad de determinar su asimilación y su intencionalidad. Asimismo, se menciona el concepto de fake news de Marc Amorós y ciertos hechos que las antecedieron. También se presentan dos casos que muestran las posibilidades de manipulación de imágenes establecidas por la inteligencia artificial (IA) considerados como Deepfake.

Finalmente se describe y analiza un anuncio que se encontró al navegar por internet como consecuencia del cruce de datos proporcionados y su combinación con los protocolos de búsqueda. Éste, además de sintetizar el objetivo de este artículo, sirve como ejemplo para distinguir la intencionalidad de la información que transita en la red. 


\section{El momento actual determinado a partir del} primer trimestre del 2020

D esde el final del año 2019, el 2020 y los primeros meses del 2021 se ha venido desarrollando la pandemia ocasionada por la enfermedad covid-19' que ha afectado, a través de diferentes maneras directas o indirectas, a múltiples actividades cotidianas de gran parte de la población mundial. Sin duda este mal será determinante en el futuro cercano de la humanidad y representa el primer factor abordado en este documento.

La covid-19 se ha propagado rápidamente y de manera exponencial desde el oriente hacia el occidente del planeta causando numerosas muertes e importantes incidencias socioeconómicas y mentales en una sociedad que ya padecía otros males. A partir de diversas investigaciones científicas realizadas por la OMS y con el apoyo de otras instituciones se ha detectado que esta enfermedad se adquiere por el contacto físico entre personas. La transmisión del virus se puede dar tan sólo con que una persona se encuentre infectada o sea portadora y salude con la mano, con un abrazo o con un beso a otra. También se puede contagiar al momento de expedir pequeñas gotas provenientes de la nariz o boca, al estornudar, toser o hablar. Otra manera de transmisión se da al tener contacto con objetos o superficies que han sido contaminadas por el virus y posteriormente tocar nuestros ojos, boca o nariz. Por tal razón, una medida sanitaria fundamental es el lavado frecuente de las manos con agua, jabón o con desinfectante.

La Universidad Johns Hopkins (JHU) se ha sumado al estudio del impacto mundial de la pandemia de covid-19, a través de la publicación de su revista especializada en medicina la cual presenta artículos relacionados con esta situación. Simultáneamente su centro de investigación de coronavirus organiza distintas actividades, entre las cuales destaca Covid-19 Contact Tracing ${ }^{2}$. Este curso en colabora- ción con Coursera - una reconocida plataforma en líneatiene como objetivo enseñar, desde el nivel elemental, las herramientas necesarias para que se sumen más personas al seguimiento de contactos de covid-19 en cada región del planeta. Además de esta iniciativa, una de las aportaciones más importantes de la JHU es la publicación de la infografía dinámica del mapa mundial que presenta visualmente la progresión de la enfermedad en tiempo real en su sitio de internet. De igual manera, se expone a detalle el número total de los casos confirmados, los sospechosos y los decesos. Esta información es proporcionada por las instituciones gubernamentales de salud de cada país. En consecuencia, la infografía consultada el 11 junio de 2020 en el portal jhu.edu, expone datos regionales y globales.

Perteneciente a la familia de los coronavirus, el virus que ocasiona la covid-19 representa un grave problema de salud pública mundial. Además de que su descubrimiento es reciente y, por tal motivo, las investigaciones sobre sus particularidades, los tratamientos requeridos y las posibles consecuencias que se pueden suscitar representan dos aspectos que agravan aún más esta situación. El primero radica en que los síntomas que presenta esta enfermedad se encuentran en prácticamente todo el planeta variando según las características de sus habitantes: edad, padecimientos generados anteriormente como obesidad, hipertensión, diabetes, enfermedad pulmonar obstructiva crónica (EPOC), entre otros; además de la exposición a posibles focos de contagio como son los espacios que concentran a un gran número de personas. Como se ha mencionado, el brote de este virus parcialmente conocido es reciente $y$, por tal motivo, el segundo aspecto se refiere a que continúan los procesos de investigación pautados por la OMS. En consecuencia, se presentan nuevos datos a cada instante que se mantienen bajo la verificación científica; por lo tanto, en el periodo de elaboración de este artículo, aun no se cuenta con conclusiones definitorias. Esta situación ha

1 "La COVID 19 es la enfermedad infecciosa causada por el coronavirus que se ha descubierto más recientemente. Tanto este nuevo virus como la enfermedad que provoca eran desconocidos antes de que estallara el brote en Wuhan (China) en diciembre de 2019. Actualmente la COVID 19 es una pandemia que afecta a muchos países de todo el mundo". (OMS, 2020)

2 Para más información relacionada al curso consultar: https://www.coursera.org 
permitido la generación de especulaciones y de interpretaciones particulares que han evidenciado, pero no ocasionado, el escenario actual de desinformación, el cual representa el segundo factor de estudio de este artículo.

Tomando en consideración que la pandemia de covid-19 representa un problema global, se observará su impacto en ciertas regiones del planeta, haciendo mayor énfasis en México a través de las reacciones del Cobierno Federal y de otros sectores sociales.

A finales del mes de febrero del 2020 se detectaron los primeros casos de covid-19 en México. En respuesta, el Gobierno de México (GM), apoyado por la Secretaria de Salud (SS), establecieron a mediados del mes de marzo del mismo año la estrategia para combatir esta pandemia, la cual ha tenido el apoyo de la OMS. Teniendo en cuenta la precariedad de la infraestructura de salud, la desigualdad socioeconómica-que son herencia de administraciones pasadas-y las características del contagio de este virus, se adoptaron las acciones estratégicas que a continuación serán descritas. Lograr el equilibrio entre los sistemas socioeconómicos y de salud de un país como México, el cual cuenta con enormes discrepancias y profundos rezagos, representa un importante desafío para el gobierno actual y para cualquier otro.

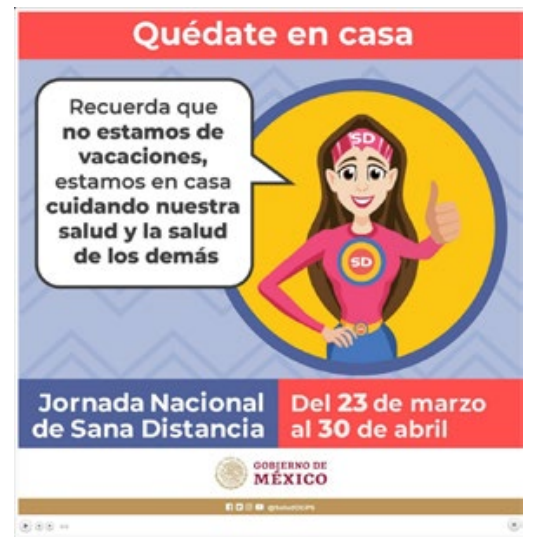

Figura 1: Esta imagen muestra el periodo de la Jornada Nacional de Sana Distancia. A partir de un mensaje realizado por la superheroína, se hace el recordatorio para permanecer en casa y no confundir el

periodo de aislamiento con vacaciones. (Secretaría de Salud, 2020)
Resulta relevante destacar que este artículo no tiene como propósito evaluar las medidas adoptadas por el GM, la SS, la OMS o la JHU u otras instancias. En primer lugar, porque no se cuenta con el dominio disciplinario correspondiente, ni con los conocimientos científicos y técnicos para realizar dicha evaluación. En segundo, porque al momento de desarrollar este documento resulta prematuro conocer las consecuencias de las medidas que han sido adoptadas. Pese a esto, las reflexiones construidas están apoyadas por los conocimientos y herramientas desde la perspectiva del diseño gráfico que participa en la emisión de mensajes que utilizan imágenes y textos que permiten el análisis de los ejemplos expuestos que han sido transmitidos durante la pandemia de covid-19.

Como ejemplos de las acciones emprendidas por el GM se presentan imágenes de las campañas de "Susana Distancia” y "Quédate en Casa”. Para la primera se utilizó la combinación del juego de palabras su sana distancia y el diseño de una superheroína Ilamada Susana. Este personaje ha comunicado desde entonces las medidas de prevención y de combate de la enfermedad, así como otras que son necesarias para el convivio social durante esta situación. A continuación, se expone la secuencia de imágenes que fueron obtenidas del portal de internet de la SS.

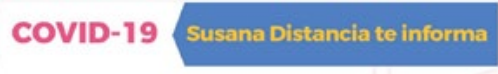

Si tengo que ir al supermercado, voy solo y procuro una sana distancia mientras hago fila

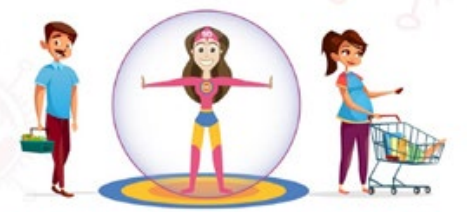

¡Si te cuidas tú, nos cuidamos todos!

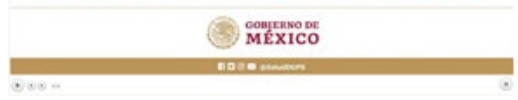

Figura 2: Este esquema destaca la extensión de los brazos de Susana Distancia, la cual indica el espacio que debe haber entre las personas que realizan una actividad cotidiana; por ejemplo, ir al supermercado. (Secretaría de Salud, 2020) 


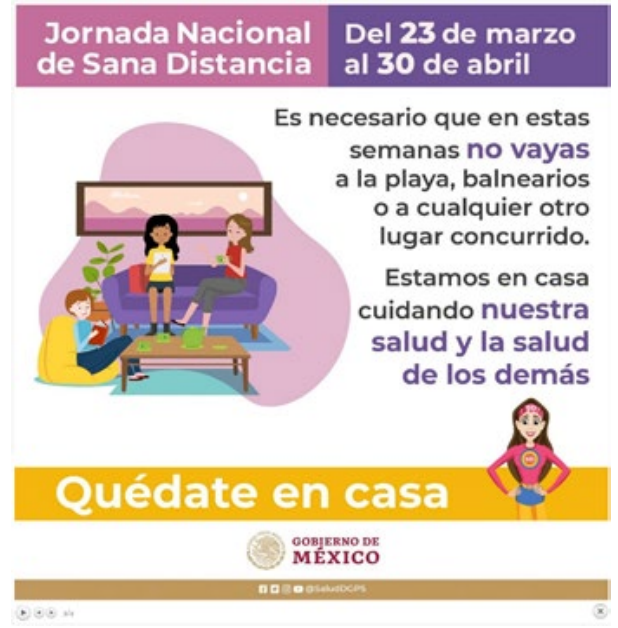

Figura 3: Nuevamente esta imagen enfatiza el periodo de la Jornada Nacional de Sana Distancia. Cabe señalar que coincidieron algunos días de esta temporada con la Semana Santa del 2020 que fue del 5 al 11 de abril. Como parte de la intención de cuidar la salud de la población, el mensaje de este esquema invita a evitar lugares concurridos, durante este lapso de tiempo. (Secretaría de Salud, 2020)

\section{Lidiando con COVID-19}

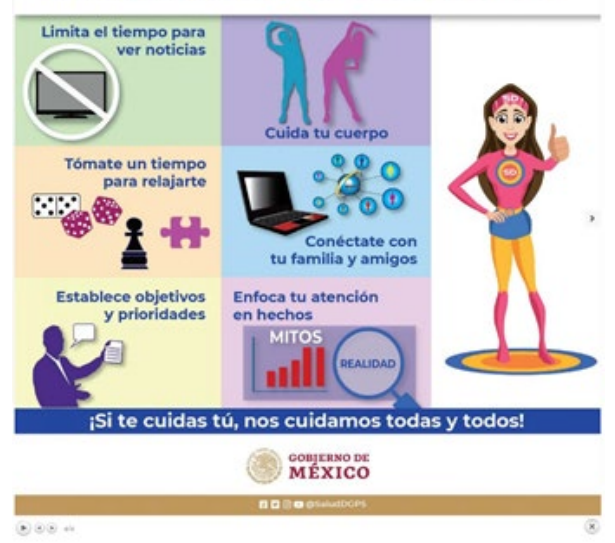

Figura 4: Para combatir la pandemia del covid-19, la SS sugiere seis medidas que son: limitar el tiempo para ver noticias, dedicar un

lapso de tiempo para hacer ejercicio, relajarse, entrar en contacto con familiares y amigos, establecer objetivos y prioridades, y finalmente tomar en consideración los hechos reales. (Secretaría de Salud, 2020)

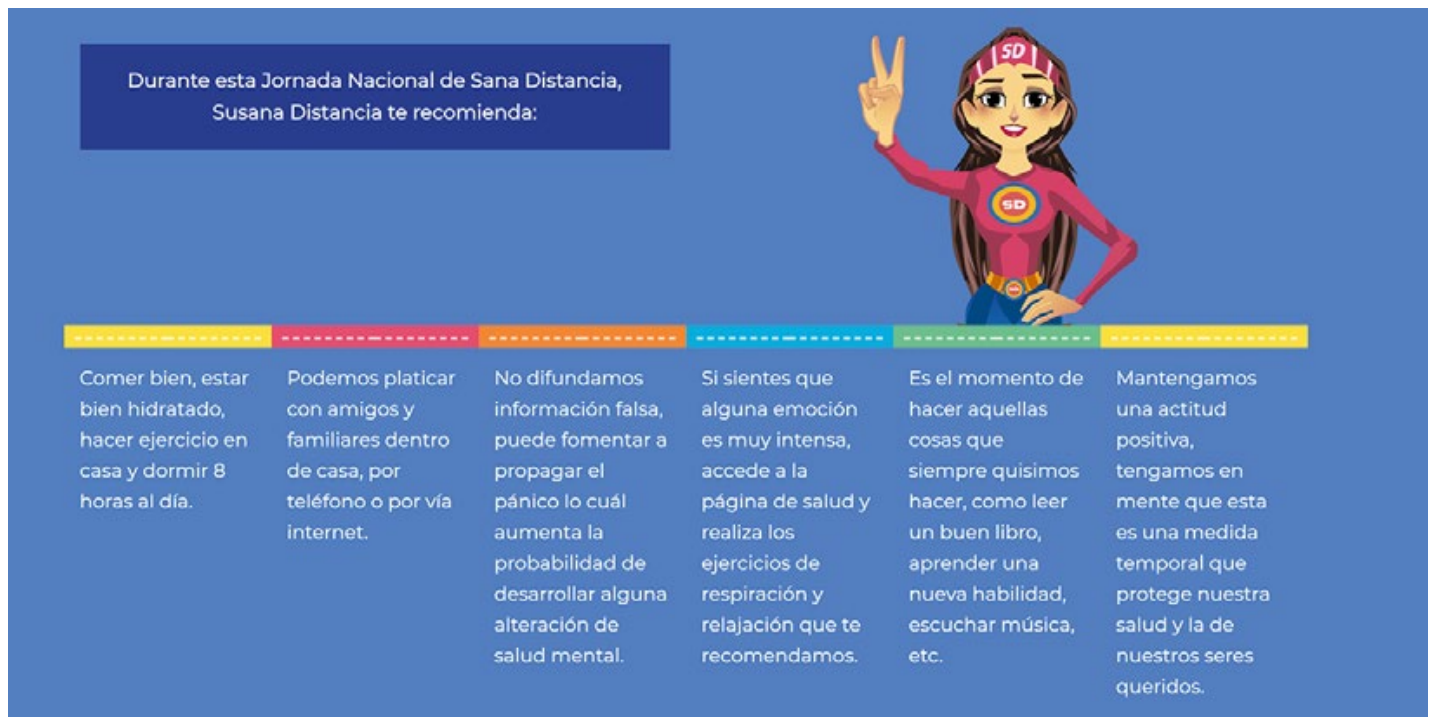

Figura 5: Esta imagen divulga seis recomendaciones de la SS comunicadas a través de Susana Distancia. Cabe señalar que la tercera convoca a no difundir información falsa, con lo cual se fomenta el pánico y la alteración de la salud mental de la población. (Secretaría de Salud, 2020) 
La publicación del diario El Porvenir del 26 de marzo del 2020 a través de su portal de internet muestra como Perla Bazán, una estudiante del Tecnológico de Monterrey campus Estado de México y Christian García, un profesor de la misma institución y publicista de Chancla Media Studio, participaron en la adaptación de la ilustración de Susana Distancia en prácticamente todos los medios de divulgación. La SS les envió el diseño aprobado de acuerdo a su estrategia de comunicación basada en la participación de una superheroína, la cual se dirige a la población mexicana. Perla y Christian tuvieron poco tiempo para diseñar otros personajes y además crearon múltiples materiales visuales como animaciones. En su conjunto, esta serie de adaptaciones tuvieron como objetivo comunicar los mensajes producidos por la SS. Cabe destacar que la figura 4

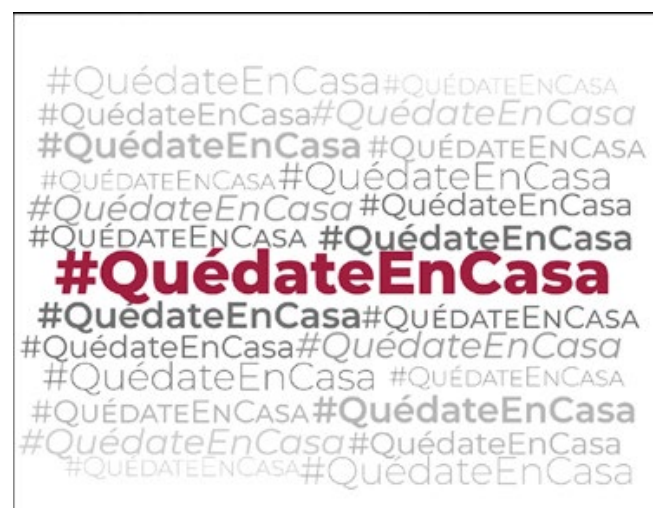

¡Si te cuidas tú, nos cuidamos todas y todos!
Figura 6: Este esquema dispone el manejo tipográfico del hashtag \#QuédateEnCasa utilizado en redes sociales. Además, hace un llamado para que esta medida sea tomada de manera individual y colectiva. (Secretaría de Salud, 2020) hace referencia a limitar el tiempo para ver noticias, mientras que la figura 5 sugiere no difundir informaciones falsas. Estos puntos que contribuyen a la desinformación, cobrarán mayor relevancia más adelante.

La segunda campaña retoma la exposición y el tránsito en espacios concurridos como un factor importante de contagio. Por tal motivo y considerando las características expuestas anteriormente, la estrategia del CM consideró el aislamiento voluntario como medida para mitigar el contagio. Inclusive teniendo en consideración las difíciles condiciones laborales y económicas de la mayor parte de la población del país, se ha insistido en permanecer en casa. Para intensificar este mensaje, sobre todo en las redes sociales como Twitter, se creó el hashtag \#QuédateEnCasa. Dos esquemas ilustrativos están expuestos a continuación:

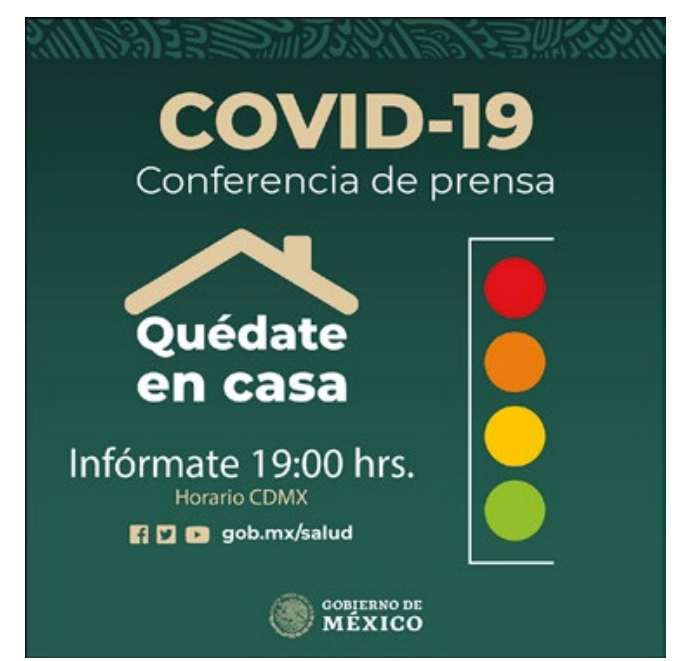

Figura 7: Esta imagen además de contar con el mensaje "Quédate en casa", anuncia el horario y los canales de transmisión de la conferencia de prensa presentada por personal de la SS, la cual se ha realizado ininterrumpidamente desde que inició la pandemia en México. (Secretaría de Salud, 2020) 
La figura 6 muestra el manejo tipográfico que recurre a la repetición de la frase "Quédate en casa". Al utilizar distintos niveles de saturación del color negro, la leyenda más obscura queda destacada en el centro de la composición. Por otra parte, la figura 7 además de presentar el mensaje ya mencionado, utiliza la abstracción del techo de una casa para enfatizarlo y anunciar la conferencia de prensa presentada por el personal de la SS. De igual manera, se muestra el semáforo de riesgo. ${ }^{3}$

Continuando con la estrategia del GM cuyo propósito central ha sido controlar la propagación del virus, desde el 23 de marzo al 30 de mayo se decretó la Jornada de Sana Distancia, como lo muestra la figura 1, la cual consistió en el cierre de espacios de gran aforo como centros comerciales y de espectáculos, gimnasios, estadios, instituciones educativas, museos y parques públicos (los cuales no cerraron totalmente, pero tuvieron restricciones de circulación). Estos recintos tuvieron que adaptarse a estas circunstancias para continuar ofreciendo sus actividades que inicialmente fueron contempladas de manera presencial y migraron hacia la virtualidad. La nueva normalidad ${ }^{4}$ experimentada durante la pandemia ha sido proyectada para un futuro próximo, lo cual permite que las rutinas de ejercicios físicos en lugar de practicarlas in situ, se realicen acompañando vídeos ya sea síncronos o asíncronos. Parte de los espectáculos de distintos géneros son presentados a través de grabaciones hechas con anterioridad y además se transmiten en vivo, vía streaming.

Particularmente en México, se suspendió la liga oficial de futbol, pero se estableció paralelamente un torneo virtual utilizando vídeo juegos para recrear los enfrentamientos entre los equipos que optaron en participar bajo esta modalidad. También se incentivaron los recorridos virtuales, como si fuesen visitas guiadas en distintos museos y recorridos culturales. Las instituciones educativas han migrado paulatinamente sus actividades académicas y administrativas hacia el entorno virtual. A pesar de que la mayoría de las tiendas de autoservicio permanecieron

3 El semáforo de riesgo epidemiológico para transitar hacia una nueva normalidad, es un sistema de monitoreo para la regulación del uso del espacio público de acuerdo con el riesgo de contagio de covid-19.

Este semáforo será estatal y está compuesto por cuatro colores:

Rojo: Se permitirán únicamente las actividades económicas esenciales, asimismo se permitirá también que las personas puedan salir a caminar alrededor de sus domicilios durante el día.

Naranja: Además de las actividades económicas esenciales, se permitirá que las empresas de las actividades económicas no esenciales trabajen con el 30\% del personal para su funcionamiento, siempre tomando en cuenta las medidas de cuidado máximo para las personas con mayor riesgo de presentar un cuadro grave de covid-19, se abrirán los espacios públicos abiertos con un aforo (cantidad de personas) reducido.

Amarillo: Todas las actividades laborales están permitidas, cuidando a las personas con mayor riesgo de presentar un cuadro grave de covid-19. El espacio público abierto se abre de forma regular, y los espacios públicos cerrados se pueden abrir con aforo reducido. Como en otros colores del semáforo, estas actividades deben realizarse con medidas básicas de prevención y máximo cuidado a las personas con mayor riesgo de presentar un cuadro grave de covid-19.

Verde: Se permiten todas las actividades, incluidas las escolares. (Gobierno de México, 2020)

4 El Gobierno de la Ciudad de México, a través de su portal de internet, hace mención de lo siguiente: "Hacia una nueva normalidad. Regresaremos más fuertes pero distintos. Lo vivido en estos meses nos hace reflexionar, aprender e innovar sobre nuestras actividades, nuestro bienestar y la convivencia urbana.

Construiremos juntos una Nueva Normalidad en la Ciudad de México sustentada en la igualdad de derechos para garantizar el acceso igualitario y generalizado a los derechos económicos, políticos, sociales y culturales con el fin de disminuir las desigualdades, las cuales solo se hicieron más evidentes en esta emergencia sanitaria". Para ello, destaca cuatro puntos: "Tener una convivencia más humana y solidaria, replantear la relación con el espacio urbano, así con el medio ambiente de tal manera que cause un menor impacto en él e invita a participar en una sociedad más justa”. (Gobierno de la Ciudad de México, 2020) 
abiertas, el comercio en línea ha presentado perspectivas de crecimiento. ${ }^{5}$ Estas prácticas síncronas o asíncronas, en otras palabras, transmitidas en vivo o preparadas con anticipación, representan el proceso de adaptación de lo presencial hacia lo virtual. Cabe destacar que estas dinámicas no surgieron durante la pandemia. A partir del entorno digital se pretende combinar las actividades presenciales con las virtuales teniendo como objetivo que la mayor parte de la sociedad continúe realizando sus actividades, lo cual representa un reto crucial.

En contraparte, se produjeron una serie de respuestas a las medidas tomadas por el CM permeadas por la crítica. Éstas en principio, deberían ampliar el abanico de opciones que contribuyan al combate de la epidemia. Sin embargo, ciertos medios de comunicación, se han encargado en difundir noticias falsas, denominadas fake news, las cuales se han distribuido en distintos canales como la prensa escrita y televisada, y las redes sociales. Estas noticias se han presentado principalmente a través de mensajes que contienen datos e imágenes manipuladas y descontextualizadas.

El martes 14 de abril de 2020 el periódico El Diario de Juárez publicó en su portada una fotografía que difundía la supuesta muerte de 80 pacientes de covid-19 en el Hospital Ceneral Regional (HGR) Número 66 de Ciudad Juárez, Chihuahua, tal y como fue documentado por el periódico infobae.com, consultado el 12 de junio. Ésta y otras imágenes fueron retomadas de un vídeo que no corresponde con lo que sucedió en este lugar y en el momento establecido. Las imágenes en cuestión no sólo aparecieron en este diario local, sino que también se publicaron en diversas cuentas de Twitter, las cuales denunciaban las deficiencias de la atención médica en otros lugares, como Estados Unidos y España. Estas fotografías extraídas del vídeo mencionado fueron analizadas por el diario español El Plural y corroboradas por Agence France-Presse (AFP), tal y como fue consultado el día 12 de junio en los portales factual.afp.com y elplural.com. El vídeo original fue grabado en el Hospital Ceneral del Norte de Cuayaquil "Los Ceibos", en el mes de marzo tal y como lo documenta AFP:
Consultado por la AFP sobre si la grabación había sido hecha en sus instalaciones, el Hospital Ceneral del Norte de Cuayaquil "Los Ceibos" respondió con el siguiente comunicado: En relación al video que circula en redes sociales, en donde se observan áreas con cuerpos sin vida y contenedores que salen, del Hospital General del Norte de Cuayaquil "Los Ceibos", del IESS, informamos que los cadáveres de los pacientes contagiados por covid-19 permanecen en la morgue del Hospital, por-al menos- 24 horas, para luego ser trasladados en contenedores refrigerados al camposanto Parque de La Paz u otras entidades, para su respectivo sepelio. (AFP Factual, 2020)

A pesar de que fácilmente es creíble, la noticia principal de El Diario de Juárez presenta los tres elementos para considerarla una noticia falsa. Tal y como lo refiere Marc Amorós (2018), en primer lugar, cuenta con un encabezado que impacta: "Prueban con fotos muerte por Covid"; enseguida, relata la indignante revelación del "maquillado" de cifras oficiales y, finalmente, tiene la apariencia de ser una noticia legitima y confiable.

En México, el 20 de marzo de 2020, el espacio informativo Imagen Televisión-consultado en youtube.com el 10 de junio del mismo año-presentó una serie de gráficas y tablas comparativas de la evolución de la pandemia de covid-19 entre China, Italia, Estados Unidos y México, sin mencionar la fuente de referencia. En la primera parte se distinguen las cifras de casos de covid-19 en el mundo y de muertes siendo 275,429 y 11,397 respectivamente. Enseguida, aparecieron los números de ese día de los cuatro países mencionados:

\begin{tabular}{l|c|c|c|c} 
País & China & Italia & Estados Unidos & México \\
\hline Casos & 81,218 & 47,021 & 19,624 & 203 \\
\hline Muertes & 3,259 & 4,032 & 260 & 2
\end{tabular}

Fuente: Elaboración propia a partir de la información del noticiario consultado en youtube.com el día 10 de junio.

5 A partir de estimaciones de la Asociación Nacional de tiendas de autoservicio y departamentales, publicado el 30 de abril, se contempla que el comercio digital aumente $66.66 \%$. (ANTAD 2020) 
Como no se demostró la fuente de referencia, para corroborar y contrastar esta información se accedió a la conferencia de prensa del personal de la SS del día 20 de marzo -consultada en facebook el 10 de junio-y nuevamente al portal jhu.edu y se constató que las cifras referentes a México de 203 casos y de 2 muertes acumuladas coinciden con lo que expuso el noticiero. A partir de los datos del portal de la JHU se estructuró la siguiente tabla:

\begin{tabular}{l|r|r|r|r|r} 
& $\begin{array}{l}\text { Registro } \\
\text { de casos }\end{array}$ & $\begin{array}{l}\text { Casos } \\
\text { diarios }\end{array}$ & $\begin{array}{l}\text { Casos } \\
\text { acumulados }\end{array}$ & $\begin{array}{l}\text { Muertes } \\
\text { diarias }\end{array}$ & $\begin{array}{l}\text { Muertes } \\
\text { acumulada }\end{array}$ \\
\hline China & 81,300 & 94 & 81,250 & 4 & 3,253 \\
\hline Italia & 277,400 & 30,773 & 277,352 & 1,486 & 11,469 \\
\hline $\begin{array}{l}\text { Estados } \\
\text { Unidos }\end{array}$ & 20,100 & 6,374 & 20,063 & 106 & 372 \\
\hline México & 203 & 39 & 203 & 0 & 2
\end{tabular}

Fuente: Elaboración propia a partir de la información consultada en jhu.edu el día 10 de junio.

La tabla presentada por el espacio informativo no específica la tipología, es decir no se clarifica si se trata de casos diarios o acumulados. Este hecho permite constatar, por una parte, que como las únicas cifras que coinciden son las de México, entonces se deduce que lo expuesto se trata de los casos y las muertes acumuladas. Por la otra, existen diferencias significativas; por ejemplo: la cantidad de casos acumulados en Italia reportada por el noticiero fue de 47,021 mientras que la JHU señaló que fueron 277,352. Si se tratara de muertes diarias o acumuladas, tampoco coinciden los datos.

El segundo comparativo, representado por una gráfica, expone la evolución de la pandemia en estos cuatro países a partir del primer día, el décimo y el vigésimo segundo, siendo este último el 20 de marzo. Cabe destacar que al realizar un estudio comparativo o de progresión, como en este caso, es fundamental contar con la precisióny homologación de los datos, en esto caso los temporales. De acuerdo con lo que reportó el noticiero, para el 20 de marzo, la evolución de los casos fue de la siguiente manera: México 203, Estados Unidos 13, Italia 21 y China 440; para el décimo día: México 7, Estados Unidos 6, Italia 3 y China 41; y finalmente para el primero: México 1, Estados Unidos 1,
Italia 2 y China 1. Al haber ambigüedad con las fechas es necesario continuar deduciendo; si el vigésimo segundo día equivale a la fecha de transmisión del 20 de marzo, por lo tanto, el primer día sería el 28 de febrero y el décimo el 8 de marzo del mismo año.

Sin embargo, como se ha destacado, la pandemia no brotó de manera uniforme, sino que se ha manifestado en distintos momentos a lo largo del planeta. Nuevamente al hacer referencia al portal de jhu.edu se realiza el siguiente comparativo de la evolución en China y México a partir de las fechas destacadas por el noticiario.

\begin{tabular}{l|r|r|r|l|l}
$\begin{array}{l}\text { Día 10 } \\
\text { 8/03/2020 }\end{array}$ & $\begin{array}{l}\text { Registro de } \\
\text { casos }\end{array}$ & $\begin{array}{l}\text { Casos } \\
\text { diarios }\end{array}$ & $\begin{array}{l}\text { Casos } \\
\text { acumulados }\end{array}$ & $\begin{array}{l}\text { Muertes } \\
\text { diarias }\end{array}$ & $\begin{array}{l}\text { Muertes } \\
\text { acumuladas }\end{array}$ \\
\hline China & 80,800 & 53 & 80,823 & 28 & 3,100 \\
\hline México & 7 & 0 & 7 & 0 & 0 \\
\hline $\begin{array}{l}\text { Día1 } \\
\text { 28/02/2020 }\end{array}$ & $\begin{array}{l}\text { Registro de } \\
\text { casos }\end{array}$ & $\begin{array}{l}\text { Casos } \\
\text { diarios }\end{array}$ & $\begin{array}{l}\text { Casos } \\
\text { acumulados }\end{array}$ & $\begin{array}{l}\text { Muertes } \\
\text { diarias }\end{array}$ & $\begin{array}{l}\text { Muertes } \\
\text { acumuladas }\end{array}$ \\
\hline China & 78,900 & 328 & 78,928 & 44 & 2,790 \\
\hline México & 0 & 1 & 1 & 0 & 0
\end{tabular}

Fuente: elaboración propia a partir de la información consultada en jhu.edu el día 10 de junio.

A partir de los datos de la JHU, el primer día de la pandemia en México corresponde al 28 de febrero del 2020, hubo un caso; mientras que, para China, donde surgió la pandemia, es el 23 de enero del mismo año y el número de casos acumulados fue de 78,928. Al no especificar la fecha, tal y como lo hizo el noticiario es posible presentar el mismo número de casos en ambos países en el día que surgieron, lo cual no fue así como ha sido comprobado.

Este hecho demuestra la manera en la que los datos al no ser citados y contextualizados adecuadamente y presentarlos de manera imprecisa, simplificada y sesgada, ocasionan la producción de noticias falsas, las cuales son difundidas por medios de comunicación como noticieros, periódicos y redes sociales.

La desinformación al estar acompañada por la división de posturas y opiniones, también denominado polarización, no representa una consecuencia de la pandemia del covid-19 en México y en el resto del mundo. Se trata de una problemática que ha estado presente en la sociedad actual y se ha acentuado en esta contingencia sanita- 
ria. Bajo esta perspectiva surge la siguiente pregunta: ¿el diseño y los avances tecnológicos inciden en esta situación, y si así fuese de qué manera participan en la Sociedad de la Información? En la siguiente sección se proponen las respuestas a esta interrogante.

\section{La Sociedad de la Información y el diseño gráfico}

El diseño gráfico está en todas partes. La actual mención, aparentemente ambigua, permite enfatizar la importancia de la disciplina, así como de otras actividades relacionadas con la comunicación visual. Esta omnipresencia se vislumbra a través de la generación de mensajes compuestos por formas, letras, colores e imágenes. Tal y como lo indica el inicio del párrafo, el diseño está presente en todas partes, desde la señalización de los espacios públicos y privados, las campañas publicitarias, los empaques, los libros y los contenidos de la red, por mencionar algunos. A partir de esta perspectiva, el diseño gráfico proporciona significado a los mensajes. Para que esto se concrete, es necesario advertir que los datos son ingredientes fundamentales en todo proceso de comunicación e información. Davenporty Prusak (1998) establecen que "los datos son un conjunto de hechos discretos y objetivos de un acontecimiento".

Su importancia es vislumbrada desde varias aristas y cabe destacar que en sí mismos representan poco o nada. Su composición se limita a la combinación alfabética o numérica que puede dar como resultado los adjetivos, los nombres propios o las cifras y por esa razón estudiarlos, compararlos, contextualizarlos y verificarlos resulta imprescindible, como se verá más adelante. A partir de los avances tecnológicos y la utilización cada vez más frecuente de computadoras y de otros dispositivos digitales se ha intensificado la recolección y el análisis de datos; por este motivo ha sido necesario encontrar la manera de estudiarlos. A este fenómeno se le conoce, a grandes rasgos, como Big Data. Al traducir textualmente esta expresión del inglés al español, se le podría nombrar como el "Gran Dato", sin embargo, su definición es más amplia. Walter Sosa (2019) define Big Data como el "...volumen y tipo de datos provenientes de la interacción con dispositivos interconectados, como teléfonos celulares, tarjetas de crédito, cajeros automáticos, relojes inteligentes, computadoras personales, dispositivos de GPS y cualquier objeto capaz de producir información y enviarla electrónicamente a otra parte".

Dando secuencia a lo anterior y continuando con las aseveraciones realizadas por Davenport, Prusak y Sosa, resultaría un error definir al dato como información. A partir del procesamiento de los datos, la verificación de su autenticidad y su relación con un contexto especifico, ya sea geográfico, temporal, o de otra naturaleza, es posible entonces contemplar la construcción de la información. En resumen, los datos inicialmente representan poco o nada, sin embargo, al procesarlos se obtienen uno o múltiples significados.

La transformación del dato hacia la información ocurre desde hace mucho tiempo. Armand Mattelart documenta que en el siglo XVIII Francis Bacon, pionero de la criptografía, declaró que "la virtud de las cifras es triple: leerlas y escribirlas no exige mucho trabajo; es imposible descifrarlas; y, en ciertos casos, están más allá de toda sospecha" (Mattelart, 2007). Años después, Cottfried Wilhelm Leibniz, considerado por Norbert Wiener como el santo patrono de la cibernética utilizó el lenguaje binario para comprimir las informaciones con el fin de economizar el pensamiento. Estos acontecimientos han contribuido a establecer la importancia de los avances tecnológicos digitales, los cuales son cada vez más determinantes en los procesos de comunicación de la actualidad. Como se verá más adelante, la producción y transmisión de la información prácticamente inmediata han provocado la simplificación del pensamiento crítico como uno de los rasgos característicos de la Sociedad de la Información del siglo XXI

El concepto de "Sociedad de la Información" fue acuñado por el sociólogo Yoneji Masuda en su libro La Sociedad Informatizada como Sociedad Post-Industrial de 1981. Tal y como su libro lo indica la Sociedad de la Información es consecuencia de la Sociedad Industrial y substituye al factor productivo basado en la producción masiva de 
tangibles por la de intangibles desarrollada por los medios de comunicación y de información. Salvat y Serrano (2011) apuntan también lo siguiente: “...la información pasa a ser en esas sociedades postindustriales el elemento decisivo en torno al cual gira el proceso productivo, pero también determinante de la evolución social en su conjunto". En consecuencia, al asumir la condición generalizada de la información en la sociedad actual, es posible que se trivialice y se asuma como obvia, que no necesita ser cuestionada o problematizada.

Mattelart (2007), por su parte, se refiere a la uniformización y a la globalización como dos factores determinantes en la conceptualización de la Sociedad de la Información. Una de las circunstancias que propician las condiciones de la uniformización es la manera como se genera la información, que está basada en los datos recolectados o producidos a partir de la lógica informática, cuya estructura parte de la perspectiva digital. Para lograr que la información producida se transmita rápidamente, se recurre a la codificación de los datos que la componen a partir del código binario.

La globalización ha permitido la expansión acelerada y la omnipresencia de la información. Una serie de datos que forman parte de una información local son producidos y difundidos en instantes de manera global. Tal y como sucedió con la noticia local del probable surgimiento del brote de covid-19, originado en el mercado de Huanan, de la ciudad china de Wuhan, que se caracterizaba por las precarias condiciones de higiene y el comercio ilegal de especies animales. Tanto la información como el virus se diseminaron rápidamente desde Asia, cruzando el resto de los continentes hasta llegar finalmente a América. Complementando esta descripción, para Manuel Castells la globalización en materia de la información está relacionada con los cambios tecnológicos de la siguiente manera:

Una revolución tecnológica, centrada en torno a las tecnologías de la información, empezó a reconfigurar la base material de la sociedad a un ritmo acelerado. Las economías de todo el mundo se han hecho interdependientes a escala global, introduciendo una nueva forma de relación entre economía, Estado y sociedad en un sistema de geometría variable. (Castells, 2000)

Esta relación ha sido fundamental para que se produzca cada vez más información, que se transmita prácticamente al mismo momento que se origina y que sea recibida en la mayor parte del planeta; esto representa la tónica principal de la Sociedad de la Información en las últimas décadas. Asimismo, el control de la producción y la emisión de la información ha estado desde finales del siglo XIX, aproximadamente, en manos de los medios de comunicación convencionales, ${ }^{6}$ de los gobiernos y en menor medida de las instituciones académicas.

Desde entonces hasta la actualidad estas instancias han colaborado de manera multidisciplinaria e incluso interdisciplinaria. Basarab Nicolescu (1996) define la multidisciplina como "...el estudio de un objeto de una sola y única disciplina por varias disciplinas a la vez", mientras que "...la interdisciplinariedad se refiere a la transferencia de métodos de una disciplina a otra”. Ambos niveles de disciplinariedad permiten la contribución de conocimientos y metodologías de distintas disciplinas con la finalidad de crear nuevos conocimientos. El diseño gráfico no ha sido ajeno a esta situación. Rudinei Kopp (2013) asume que "la actividad del diseño gráfico, materialmente une: tipografía, fotografía, ilustración, artefinal, superficies de impresión o fijación de la información, tratamiento de imágenes, procesos industriales de impresión gráfica, entre otros". Dada la importancia de la información, vinculada con la creación y el procesamiento de imágenes, y la fijación de mensajes en la sociedad actual, es posible una vez más determinar que el diseño está en todas partes. Al considerar la combinación de esta argumentación con la del control de la producción y el flujo de la información que les corresponde a los medios de comunicación convencionales, se considera que la Sociedad de la Información funciona adecuadamente.

6 A pesar de que surgieron en épocas distintas, en la actualidad la prensa, radio, cine, televisión e internet son considerados como medios de comunicación convencionales. 
Sin embargo, no es así, ya que el entorno social se ha modificado drásticamente. Cabe destacar que esta transformación ha sido favorecida por los avances tecnológicos digitales. Nuevamente haciendo alusión a la uniformización y a la globalización, el acceso para adquirir y controlar los dispositivos digitales que permiten produciry transmitir la información ya no es exclusivo de los medios convencionales de comunicación. Esta metamorfosis ha permitido la participación de una nueva categoría, la cual se designa como los receptores-emisores. Es importante señalar que desde hace al gunos años las personas que recibían las noticias desde un televisor o un radio, actualmente tienen la opción de hacerlo gracias a las computadoras, teléfonos celulares, entre otros. También cuentan con la posibilidad de produciry transmitir información al utilizar estos dispositivos digitales.

Este fenómeno se ha incrementado con la pandemia de covid-19. Y como lo hemos ejemplificado antes, en lo publicado en el periódico infobae.com, este hecho muestra como los usuarios de redes sociales y los medios señalados difundieron imágenes que no corresponden a lo ocurrido con la noticia que compartieron. Se ha diversificado una de las actividades características del diseño gráfico y de otras disciplinas afines a la comunicación visual que participan en la Sociedad de la Información, ya que para fijar la información a partir de la creación y el tratamiento de imágenes basta con disponer de un dispositivo digital y de las aplicaciones necesarias, conocer las nociones básicas para manipularlos, contar con acceso a internet y disponer de una cuenta en alguna de las múltiples redes sociales.

La interpretación de esta situación resultaría sumamente parcial si se reducen las características de los participantes en aspectos como su edad, su condición socioeconómica, sus hábitos de consumo, sus preferencias sexuales, religiosas, políticas, o su nivel de estudios, por citar algunas. Por ejemplo, una persona que cuenta con la capacidad adquisitiva que le permita obtener los dispositivos digitales mencionados y que conozca la manera para participar en el entorno digital, no necesariamente puede ser contemplada como un emisor de información. En con- bajo nivel educativo podría formar parte de esta actividad. El escenario de la Sociedad de la Información está configurado por variables que no necesariamente participan de manera dual y sustitutiva, lo cual produce un entorno de mayor complejidad.

El concepto "informar" tiene implícito la intención de "dar forma". Bajo esta premisa, el carácter formativo establece que la acción es dirigida por el emisor hacia el receptor. La migración de las funciones inicialmente atribuidas a los emisores no representa un intercambio de actividades. Es decir, los medios convencionales no han dejado de producir información, sino que desde hace tiempo se realiza de manera colaborativa con otros que anteriormente participaban solamente cómo receptores. Esto lleva a pensar que la intencionalidad y la responsabilidad de "dar forma" no se limita a los periódicos, los noticieros, los gobiernos, o inclusive, las instituciones educativas, sino que es compartida con los receptores-emisores que, al estar equipados con dispositivos digitales, tienen el interés por generar y transmitir más información de manera rápida e inmediata.

Para ilustrar esta situación se retoman los ejemplos presentados en la primera sección de este artículo. Por un lado, las figuras 1 a la 7 que representan los mensajes de la SS, muestran que la información que transmiten está construida con datos validados por instancias como la OMS y dan como resultado mensajes que tienen la intención de prevenir y combatir la pandemia de covid-19. Por el otro, la manipulación de las imágenes del video grabado en el Hospital "Los Ceibos" de Ecuador en marzo de 2020 se utilizó para exhibir una situación sumamente delicada que en realidad no sucedió en Estados Unidos, España o en México, tal y como ha sido mencionado.

La dinámica de la Sociedad de la Información no sólo ha propiciado la diversificación de los medios de comunicación convencionales y los receptores-emisores, sino que ha permitido que cada participante imprima su propia intencionalidad. Desde una perspectiva positiva esto representaría la transmisión de datos contextualizados, contrastados y corroborados que contribuirían a la búsqueda de soluciones a los problemas actuales, como la pandemia de covid-19. Desde la perspectiva negativa, 
al descontextualizary distorsionar la información se provoca lo contrario: confusión y pánico.

El desarrollo de factores productivos en la historia de la humanidad como el esclavismo, el feudalismo, la industrialización y la información, son percibidos como un concepto trascendental para la evolución social, tal y como lo comentan Salvat y Serrano (2011). El objetivo común de cada una de estas etapas es producir cada vez más y de manera más rápida, tanto tangibles como intangibles, con el propósito de generar ganancias principalmente económicas. Pero esto no quiere decir que se contemple proporcionalmente la cantidad, la calidad y mucho menos la intencionalidad. Esta problemática ha sido recurrente en la Sociedad de la Información. Como se ha reiterado, la diversificación de la producción y la emisión de la información inicialmente atribuida al emisor es compartida con el receptor, lo cual ha permitido la democratización de la información, y en contraste, ha propiciado el imperio de la opinión sobre el conocimiento. Continuando con la indagación de estas transformaciones características de la sociedad actual, surge el siguiente cuestionamiento: ¿La pandemia de covid-19 representa el momento para replantear a la información como factor productivo? En la próxima sección de este documento se responderá a esta cuestión.

\section{El diseño gráfico y los avances tecnológicos digitales}

Se han señalado al diseño gráfico y los avances tecnológicos como dos elementos que participan en el funcionamiento de la Sociedad de la Información, los cuales se relacionan entre sí desde mucho antes del surgimiento de la pandemia de covid-19. Gran parte de las actividades que desarrolla el ser humano, como el diseño gráfico, cuentan con el apoyo de la tecnología al considerar como objetivos primordiales la sobrevivencia y el control del entorno. Es importante señalar que el grado de sofisticación de las herramientas empleadas no determina si se está recurriendo o no a la tecnología. Dicho en otras palabras, desde el momento que el ser humano, o en este caso el diseñador utiliza un lápiz o una computadora para realizar una actividad, se establece un vínculo tecnológico.
La relación del diseño y la tecnología es acentuada por Luis Rodríguez Morales (1995) al retomar el modelo del arquitecto Fernando Rovalo y López de Linares, quien contribuyó a cimentar las bases de las primeras escuelas de diseño gráfico en América Latina. Este modelo planteó la concepción del aspecto formal de un objeto de diseño a partir del diálogo entre tres esquemas conceptuales: el expresivo, el funcional y el tecnológico. Este último contempla las etapas representativas del proceso de creación y de producción de dicho objeto.

En este artículo se ha insistido en la participación de la tecnología desde su carácter evolutivo, la cual inicia desde la manufactura de objetos sencillos que evolucionaron hacia las máquinas de tipo mecánico, y enseguida al transformarse suplieron la fuerza manual por la energía eléctrica. Desde hace algunas décadas, estos artefactos han sido gradualmente substituidos por los dispositivos digitales, los cuales como se ha destacado, son determinantes en la configuración de la Sociedad de la Información.

La conjunción del diseño con los avances tecnológicos ha propiciado el aumento de la producción y la transmisión de información mediante mensajes que combinan el uso de imágenes y textos, permitiendo que sean recibidos rápidamente en casi cualquier rincón del planeta. Desde esta situación, retomando a Rudinei Kopp, la creación y la manipulación de imágenes ha sido lograda en gran medida por parte del diseñador gráfico. El autor también menciona que la fijación de la información es un factor importante. Por otro lado, Sosa (2019), subraya lo siguiente:

- En los últimos dos años, en todo el mundo hemos creado más datos que en toda la historia de la humanidad.

- Cada segundo se crean 1,7 megabytes de información nueva.

- Los usuarios de Facebook envían 31.25 millones de mensajes y miran 2.77 millones de vídeos por minuto.

- En 2015 se sacaron 1000000000000 fotos.

Como se ha destacado en la sección anterior, el aumento de los participantes y la intensidad del ritmo de pro- 
ducción y transmisión de la información es un hecho. Por lo tanto, ¿es posible determinar que ésta se asimile de la misma manera? A partir de los datos expuestos por Walter Sosa, es posible afirmar que los asiduos usuarios de redes sociales producen y reciben una vasta cantidad de información en lapsos de tiempo cada vez más cortos. Posteriormente, en la mayoría de los casos, ésta es simplemente retransmitida por lo que difícilmente puede ser comprobada o incluso comprendida. Los medios convencionales y los receptores-emisores han estado más preocupados por mantener el flujo constante de la información que por corroborarla, verificarla y en menor grado, reflexionar sobre su pertinencia. Las fake news que han sido expuestas en la primera sección de este documento son un claro ejemplo. Se caracterizan por representar un aspecto sustancial de la Sociedad de la Información.

Amorós (2018) define las noticias falsas o fake news como informaciones "...diseñadas para hacerse pasar por noticias con el objetivo de difundir un engaño o una desinformación deliberada para obtener un fin político o financiero." En la introducción de su libro, el periodista Jordi Évole declara lo siguiente: "A más información, más mentiras corriendo." Es decir, existe una relación simétrica entre el aumento de la información y las noticias falsas que circulan.

Este síntoma no es nuevo, el propio Amorós documenta que, en 1898 , el poderoso magnate estadounidense de los medios de la época William Randolph Hearst logró que España perdiera Cuba, su territorio colonial a partir de la invención mediática de una guerra entre ambos países. En el contexto actual, desde hace algunos años, las redes sociales han facilitado la diseminación vertiginosa de informaciones que no necesariamente son verdaderas, pero son creíbles. Este tipo de noticias se elaboran con la intención de favorecer a alguien o a un grupo en particular. "Las fake news no se crean por diversión, sino para obtener un beneficio. Y este puede que sea económico, político o ideológico". (Amorós, 2018) Al completar este argumento y recuperando lo mencionado en la sección anterior, es importante destacar que tanto las noticias reales como las fake news tienen intencionalidad.
A partir de la lectura del pasaje de Hearst es posible afirmar que las fake news también "dan forma". Desde la perspectiva de la intencionalidad económica, el montaje de la guerra entre España y Cuba fue producido para obtener mayores ganancias en la venta de espacios publicitarios del periódico y de sus ejemplares. Sucedió algo similar en el caso de El Diario de Juárez, mencionado en la sección anterior. La búsqueda en internet y la edición de las imágenes -las cuales han sido comprobadas que no fueron realizadas por este medio-es considerablemente menos costosa que la cobertura de los hechos por parte de periodistas y reporteros, entre otros profesionales de la comunicación. En resumen, las fake news cuestan menos dinero y pueden representar mayores ganancias económicas para quienes las producen y las transmiten.

Este tipo de noticias establecen intencionalidades ideológicas, las cuales provocan la polarización. Es posible observar este fenómeno de manera simplificada desde la división entre dos posturas, lo cual ha sido una constante antes y durante la pandemia de covid-19. En cuanto a las tendencias políticas se encuentran las diferencias entre izquierda y derecha; económicamente, entre ricos y pobres; y académicamente entre ilustrados e ignorantes. La mayor parte de la problemática de la sociedad actual se vislumbra al tratar de discernir los acontecimientos en blanco y negro, considerando principalmente la disposición endogámica, caracterizada por formar grupos afines a determinados intereses y que rechazan a los que discrepan. Ante la dificultad de establecer consensos referentes a la diversidad ideológica, la fabricación de fake news resulta tentadora. Mucho antes de que existieran las computadoras y las redes sociales, Mark Twain comentó lo siguiente: "es más fácil engañar a la gente que convencerla que ha sido engañada".

Ahora bien, si en el siglo antepasado ya existía la intención de desinformar, ¿por qué continúa siendo vigente hasta ahora? Seguramente la conjunción del diseño y los avances tecnológicos digitales tienen que ver al respecto. Un ejemplo de ello está expuesto por las posibilidades que ofrece la inteligencia artificial $(I A)^{7}$ mediante la manipulación de recursos como imágenes, textos y audios que pos-

7 "La inteligencia artificial (IA) aplica análisis avanzados y técnicas basadas en la lógica, incluido el aprendizaje automático, para interpretar eventos, apoyar y automatizar decisiones y tomar medidas". (Gartner, 2020) 
teriormente son difundidos en internet. A este respecto, se comentan dos ejemplos de Deepfake. ${ }^{8}$

El primero es un vídeo realizado por Monkeypaw Productions ${ }^{9}$ en colaboración con BuzzFeed ${ }^{10}$ y muestra un mensaje que supuestamente comunicó Barack Obama, el expresidente de los Estados Unidos. Éste fue consultado el 20 de junio en el portal youtube.com. El vídeo comienza con la presentación de Barack Obama sentado y hablando desde un espacio que podría ser la Casa Blanca. Los subtítulos en inglés coinciden con las palabras emitidas por este personaje. Aproximadamente a los 33 segundos, la pantalla se divide en dos e introduce del lado derecho a otra persona. La secuencia de este material da a entender que es Jordan Peele quien en realidad está hablando. Al imitar la voz del exmandatario y utilizar su imagen, este Deepfake permite que Peele sincronice su mensaje a partir del movimiento de labios del expresidente. Desde el principio se interpreta que el mensaje estaría siendo presentado por Barack Obama, pero en realidad no es así. A continuación, se muestra la transcripción del vídeo:

Estamos entrando en una era en la cual nuestros enemigos pueden aparentar que cualquiera puede decir cualquier cosa, en cualquier momento, y a pesar de que ellos mismos no lo dirían. Como, por ejemplo, ellos pueden simular que yo diga cosas como, no sé, "Killmonger

El segundo ejemplo destaca que el sitio Cultura Inquieta (2012) señala que el portal FacetoFake ${ }^{11}$ utilizó la fotografía de Federico García Lorca y la combinó digital- mente con el vídeo de Carmelo Gómez, consultado el 16 de junio de 2020 en el sitio youtube.com, y quien recita el poema "Casida de la muchacha dorada" del propio poeta español. El resultado obtenido es la combinación de recursos de IA que permite la declamación del poema por parte del autor. Ambos ejemplos de Deepfake destacan intencionalidades distintas. Mientras que el primero expone lo que podría suceder si una persona utiliza la imagen de otra para emitir un mensaje en particular, el segundo hace un ejercicio de la recreación de Federico García Lorca recitando su propia poesía.

En la historia de la humanidad no ha habido otro periodo en el que se produzcan y transmitan los vertiginosos flujos de información como en la actualidad. Por tal motivo, los participantes de la Sociedad de la Información no vislumbran desconocer la participación del diseño gráfico al tener en cuenta la premisa de que "está en todas partes", y mucho menos pretenden detener los avances tecnológicos digitales. La pandemia de covid-19 ha aumentado la seducción por generar cada vez más información que se caracteriza por ser accesible y gratuita. Sin embargo, ante las problemáticas resultantes del constante tránsito de noticias reales, falsas, irrelevantes o inclusive bromas, es necesario replantear la trascendencia de la información como factor productivo. Leibniz afirmaba que la aplicación del lenguaje binario permite el ahorro del pensamiento. A pesar que la información fluye más rápido, Ilega más lejos y de manera prácticamente inmediata, la función de "dar forma" está destinada hoy en día a transmitir intenciones ideológicas y económicas que resultan en acciones endogámicas.

8 "El término deepfake nació de la unión de dos conceptos: el deep learning, como se conoce al aprendizaje profundo de sistemas de inteligencia artificial y la palabra fake, falso". (CNet, 2020)9 “El término deepfake nació de la unión de dos conceptos: el deep learning, como se conoce al aprendizaje profundo de sistemas de inteligencia artificial y la palabra fake, falso". (CNet, 2020)

9 "La inteligencia artificial (IA) aplica análisis avanzados y técnicas basadas en la lógica, incluido el aprendizaje automático, para interpretar eventos, apoyar y automatizar decisiones y tomar medidas". (Gartner, 2020)

10 "La inteligencia artificial (IA) aplica análisis avanzados y técnicas basadas en la lógica, incluido el aprendizaje automático, para interpretar eventos, apoyar y automatizar decisiones y tomar medidas". (Gartner, 2020)

11 FacetoFake se describe como una referencia de "películas, series, entrevistas, vídeojuegos... con tiempo y buen material cualquier vídeo puede usarse para cambiar a sus protagonistas por otras personas. En este canal verás todo tipo de “DeepFakes”, para diversión o entretenimiento sirviendo a su vez como una gran muestra de las posibilidades de la Inteligencia Artificial”. (YouTube, 2020) 
Descripción y análisis de un anuncio encontrado en Internet

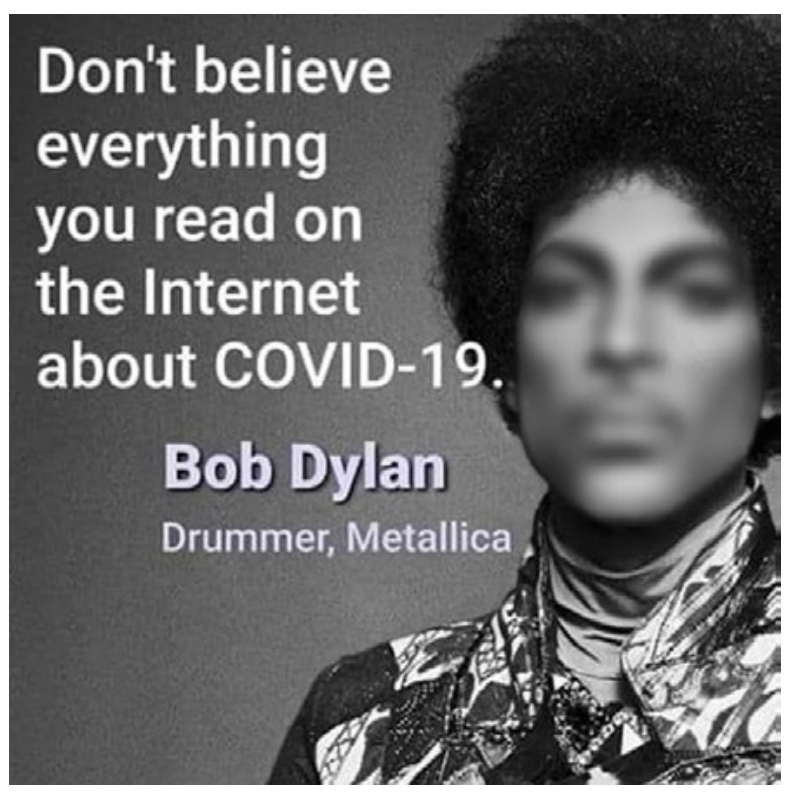

Figura 8: Este anuncio fue consultado en internet. (Democraticunderground, 2020)

A partir de tres momentos analizaré el mensaje difundido a través del anuncio de la figura 8 , el cual resume claramente lo que se ha desarrollado en este documento. Al leerlo de izquierda a derecha es posible observar en primera instancia la frase traducida del inglés al español: "No creas todo lo que lees en internet sobre covid-19". Enseguida aparecen el nombre propio "Bob Dylan"y posteriormente "Baterista, Metallica". Del lado derecho se encuentra la fotografía de una persona.

En un primer momento, al relacionar rápidamente el texto principal con la imagen y el nombre, es posible interpretar el anuncio de la siguiente manera: la fotografía corresponde a Bob Dylan, quien es el baterista de Metallica y expresó la frase mencionada. Sin embargo, como se verá más adelante, existen indicios para identificar que la intención del mensaje es otra, por lo tanto, es necesario analizarla.
Continuando con la indagación del anuncio, resulta relevante contrastar los datos. Es por ello que en un segundo momento surge la pregunta: ¿quién es Bob Dylan? Cabe la posibilidad de que no se conozca la respuesta, por lo que probablemente se realice una búsqueda rápida en internet. En caso contrario, se constataría que Robert Allen Zimmerman, conocido como Bob Dylan, es un prestigiado músico, compositor, cantante y poeta estadounidense, nacido en 1941, quien además ganó el premio Nobel de literatura en 2016. Al tener en cuenta esta información y contrastarla con la imagen del lado derecho, queda descartada la relación entre el nombre de quien emite la frase con la fotografía.

Ahora bien, al observar la imagen de la persona del lado derecho, se distingue a Prince Rogers Nelson, cuyo nombre artístico es Prince. Es importante destacar que este músico norteamericano muere el mismo año que Dylan obtiene el Nobel. Otro dato que merece ser contemplado es que ambos son músicos de distintos géneros y que ninguno de ellos ha sido baterista de Metallica de manera oficial. Metallica es un grupo estadounidense de trash metal, cuyo único baterista ha sido el danés Lars Ulrich. Tanto Dylan, Prince y Ulrich no son ficticios, son personas reales y reconocidas en la escena de la música popular de las últimas décadas.

Al realizar este análisis descriptivo, fueron detectados tres destacados músicos contemporáneos que intervienen en el mensaje de este anuncio cuando en realidad debería aparecer solamente uno. Desde este punto, el mensaje despierta sospecha sobre su credibilidad.

El tercer momento establece que estos artistas son relevantes en el medio del espectáculo, por lo tanto, existe la posibilidad de despertar el interés de los receptores de este anuncio -en especial de sus seguidores- por conocer sus respectivas posturas sobre temas relevantes como internet y la pandemia de covid-19. Probablemente alguno de ellos declaró esta frase. No obstante, Prince quien justamente es identificado en la fotografía del anuncio queda totalmente descartado ya que falleció 4 años antes del brote de la pandemia de covid-19. Este hecho permite desconfiar aún más de la veracidad del anuncio. Con respecto a 
la frase, se trata de una declaración que carece de los argumentos que sustenten si se le adjudica a Bob Dylan o a Lars Ulrich. Consecuentemente, al desconocer su autoría, por un lado, es posible determinar que el mensaje es real pero no necesariamente verdadero y por otro, identificar su verdadera intención que queda implícita en el texto: "No creas todo lo que lees en internet sobre covid-19".

\section{En conclusión}

De lo expuesto en este artículo podemos concluir que al producir y difundir noticias falsas como las que se han expuesto en este artículo, es necesaria una dosis de verdad y otra que aparenta serlo. Que los datos inicialmente son sencillos, pero adquieren múltiples significados al contextualizarlos y combinarlos y que este fenómeno se ha complejizado a partir de la vertiginosa producción y circulación por medios de comunicación convencionales y los receptores-emisores. Éstos están más interesados en satisfacer la demanda de "dar forma" de manera inmediata que en corroborar la veracidad de la información.

El análisis del anuncio que contiene la frase "No creas todo lo que lees en internet sobre covid-19" muestra el ejercicio que se puede realizar para deducir la intención de uno de múltiples mensajes que se reciben constantemente. Por lo tanto, resulta urgente tomar una pausa en los momentos ordinarios o los extraordinarios como la pandemia covid-19 para discernir una noticia real de una falsa y posteriormente reconocer su intencionalidad. La validación automática de las certezas absolutas e inmediatas expuestas principalmente en internet provoca la falsa sensación de mantenerse informado, cuando en la mayoría de las ocasiones se desinforma y lejos de resolver una problemática, favorece a situaciones endogámicas. 


\section{Referencias}

AFP Factual. ¿Estos son cuerpos en una morgue de Nueva York? (abril de 2020). https://factual.afp.com/el-video-con-decenas-de-bolsas-para-cadaveres-fue-grabado-en-ecuador-no-en-nueva-york (acceso: 12 de junio de 2020).

Amorós García, Marc. Fake News (Edición en español). Barcelona: Plataforma, 2018.

Asociación Nacional de Tiendas de Autoservicio y Departamentales A. C. (ANTAD). Información Covid-19. https://antad.net (acceso: 11 de junio 2020).

BuzzFeed. Página sobre la información de la plataforma. https://www.buzzfeed.com (acceso: 16 de junio 2020).

CNet. ¿Qué es un deepfake y por qué deberíamos saberlo? https://www.cnet. com (acceso: 16 de junio 2020).

Coursera y Johns Hopkins University of Medicine. Rastreo de contactos de COVID-19. https://www.coursera.org (acceso: 11 de junio 2020).

Cultura Inquieta. Un vídeo de García Lorca recitando gracias a la tecnología "deepfake". https://culturainquieta.com (acceso: 12 de junio 2020).

Davenport, Thomas y Laurence, Prusak. Working Knowledge. How organizations manage what they know. Boston: Harvard Business School Press, 1998.

Democratic Underground. Don't believe everything you read on the internet about covid-19. https://www.democraticunderground.com/ (acceso: 16 de junio 2020).

El Plural. Página principal del Periódico Digital Progresista. https://www.elplural.com (acceso: 12 de junio 2020).

El Porvenir. Edición del 26 de marzo de 2020. https://elporvenir.mx/ (acceso: 11 de junio 2020).

Face to Fake. Página sobre la información de la plataforma. https://www.youtube.com (acceso: 12 de junio 2020).

Gartner. Gartner Clossary, Artificial Intelligence (AI). https://www.gartner.com (acceso: 10 de junio 2020). 
Cobierno de la Ciudad de México. Nueva Normalidad. https://covid19.cdmx. gob.mx (acceso: 16 de junio 2020).

Cobierno de México. Información Ceneral - Covid-19. https://datos.covid-19. conacyt. $\mathrm{mx} /$ (acceso: 10 de junio 2020).

Semáforo de Covid-19. https://coronavirus.gob.mx/semaforo/ (acceso: 11 de junio 2020).

Infobae. Segob alista sanciones contra dos diarios de Chihuahua por publicar noticias falsas. https://www.infobae.com (acceso: 12 de junio 2020).

Johns Hopkins University of Medicine. Tablero realizado por el Sistema de Ciencia e Ingeniería de JHU. https://coronavirus.jhu.edu/map.html (acceso: 12 de junio 2020).

Kopp, Rudinei. Diseño gráfico cambiante. Ciudad de México: Ars Optika, 2013.

Mattelart, Armand. Historia de la sociedad de la información. Barcelona: Paidós, 2007.

Monkeypaw Productions. Página sobre la información de la productora. https://www.monkeypawproductions.com (acceso: 16 de junio 2020).

Nicolescu, Basarab. La transdisciplinariedad. Manifiesto. 1996. https://basarab-nicolescu.fr/

Organización Mundial de la Salud. Preguntas y respuestas sobre la enfermedad por coronavirus (COVID-19). https://www.who.int/es (acceso: 10 de junio 2020).

Rodríguez Morales, Luis. El diseño preindustrial. Una visión histórica. Ciudad de México: Universidad Autónoma Metropolitana-Azcapotzalco, 1995.

Salvat Martinrey, Guiomar y Serrano Marín, Vicente. La revolución digital y la Sociedad de la Información. Sevilla: Comunicación Social Ediciones y Publicaciones, 2011.

Secretaria de Salud. Información relacionada a la campaña de Sana Distancia [localizada en la cuenta de Facebook @SecretariadeSaludMX] https://www.facebook.com/SecretariadeSaludMX (acceso: 11 de junio 2020) 
Secretaria de Salud. Información general sobre el Coronavirus. http://www. salud.gob.mx (acceso: 11 de junio 2020).

Sosa Escudero, Walter. Big Data. Breve manual para conocer la ciencia de datos que ya invadió nuestras vidas. Ciudad de México: Siglo Veintiuno editores, 2019.

YouTube. Carmelo Gómez para \#amamoslapoesía | Condé Nast Think. https:// www.youtube.com (acceso: 12 de junio 2020).

. Casida de la muchacha dorada, por Federico García Lorca [AI]. https:// www.youtube.com (acceso: 16 de junio 2020).

Suman 203 casos y dos muertos en México por Coronavirus | Noticias con Ciro Cómez Leyva. http://www.youtube.com (acceso: 10 de junio 2020).http://www.youtube.com

. You Won't Believe What Obama Says in This Video! https://www. youtube.com (acceso: 12 de junio 2020) 


\section{Normas editoriales}

\section{DIS Journal}

Revista Semestral del Departamento de Diseño

\section{Normas editoriales para la presentación de originales}

Todo artículo, ensayo o reseña crítica que se proponga a DIS debe ser original e inédito, las principales condiciones para participar en la publicación, son:

- ser material inédito, no publicado previamente

- ser resultado de un proyecto de investigación, o ser un ensayo académico (con aparato crítico)

- no debe estar postulado simultáneamente en otras revistas

IMPORTANTE:

- La publicación se realizará en español, pero contendrá enlaces al documento en su idioma original. Esto implica periodos de traducción.

- El periodo de resultados de dictaminación con resultado positivo o negativo es de 18 MESES, mismos que se cuentan desde la confirmación de la recepción del artículo. Si el artículo fue aceptado para su publicación, y una vez atendidas las recomendaciones dictaminatorias, se colocará en la lista de espera de artículos publicables (su publicación estará contemplada en alguno de los dos números del próximo año lectivo a su aceptación). Se darán los oficios pertinentes que el autor solicite para dar aviso a sus respectivas evaluaciones.

- Los artículos con un dictaminen negativo, no podrán volver a presentarse.

- El número máximo, por publicación, es de 4 autores.

- Todo artículo será sujeto a una evaluación preliminar por el Comité de Redacción que determinará si es factible de ser sometido a dictamen, 
de acuerdo con lo estipulado en la actual pauta editorial. En caso afirmativo, el artículo será evaluado por pares asignados por el Comité Editorial, manteniendo el anonimato entre autores y dictaminadores; en caso de discrepancia, se turnará a un tercer dictaminador.

- Los editores se reservan el derecho de realizar los ajustes de estilo que juzguen convenientes.

- La recepción de un artículo no puede garantizar su publicación

Los originales deberán incluir la información siguiente:

1. Título del artículo

2. Nombre completo del autor

3. Institución a la que pertenece

4. Correo electrónico del autor

5. Un curriculum vitae breve (aproximadamente diez líneas) del autor.

6. Resumen de máximo 150 palabras, además deberá estar en dos idiomas: español y en el que este escrito el documento presentado. En el caso de las reseñas críticas, no se requiere resumen.

7. Incluir hasta cinco palabras clave después del resumen, también en los dos idiomas.

La presentación del material deberá tener el siguiente formato:

- La extensión para un artículo o ensayo será de 8,000 a 10,000 palabras; y para una reseña crítica de 2,500. Este cálculo comprenderá el texto y su aparato crítico, pero excluye resúmenes y bibliografía.

- Tipo de letra, deberá ser Times New Roman

- Tamaño de la letra, 12 puntos

- Interlineado de 1.5 líneas

- Tamaño de la página de 21.5 x $28 \mathrm{~cm}$ (tamaño carta)

- Márgenes de $3 \mathrm{~cm}$. por los cuatro lados

- La jerarquía de los títulos debe ser clara, pues será
Para ello se puede indicar la jerarquía con las siguientes características:

Título, en 14 puntos, irán en negritas, en altas y bajas, alineados al centro, dejar tres líneas en blanco, entre éste y el texto que le sigue.

Subtítulos, en 12 puntos, irán en negritas, en altas y bajas, alineados a la izquierda. Antes de un subtítulo es necesario dejar dos líneas en blanco, así como una sola línea entre éste y el texto que le sigue. El título y los subtítulos serán descriptivos y breves (no más de diez palabras).

Si hay un título de menor jerarquía al subtítulo, éste puede ir alineado a la izquierda, sin espacio entre éste y el texto que le sigue, usar un tamaño de 12 puntos y en cursivas.

1. Los trabajos se remitirán por correo electrónico a <publicaciones.diseno@ibero.mx>, en archivo procesado en Word. No se devolverán los originales recibidos.

2. Las notas deberán ser breves y se utilizarán sólo cuando sean indispensables. Deberán aparecer a final de página y no serán de carácter bibliográfico, sino de comentario. Se procesarán con el sistema de Word, es decir en el menú insertar, debe buscar nota al pie, ponerlas consecutivas y numeradas. El número de cita se pondrá después de las comillas e inmediatamente después del signo de puntuación correspondiente.

3. La bibliografía y las citas debe seguir las pautas del formato $\mathrm{CHICACO}$. Puede revisar:

http://www.chicagomanualofstyle.org/tools_citationguide.html,

http://guiasbus.us.es/bibliografiaycitas/chicago, http://guides.lib.monash.edu/citing-referencing/ chicago

http://www.journals.uchicago.edu/cont/prep-art?journal=cer\& 
4. Las citas textuales de menos de cinco líneas irán dentro del párrafo, entre comillas (") de apertura y cierre. A continuación se indicará entre paréntesis la referencia bibliográfica en este orden: apellido del autor, año de publicación, número de página (sólo el número). El punto se pone después del paréntesis. Para citas de más de 5 líneas, se sangrará, se utilizará tipografía normal de 10 puntos, no itálica. En todo momento se pueden usar corchetes, 1 se debe dejar una línea antes y después de la cita:

Algunos grabados destinados a ilustrar obras de circulación restringida, es decir, para las elites religiosas y civiles, adoptaron formas de representación comunes al grabado popular [...] El hecho de que se tratara de copias o adaptaciones de grabados más antiguos de origen europeo no acaba de explicar el fenómeno [...] estos casos serían más bien una prueba de que los límites entre el grabado populary el grabado culto no sólo eran imprecisos sino que tanto para los impresores como para el público lector novohispano, la coexistencia entre ambas formas de expresión gráfica no causaba extrañeza ni contradicción (Galí, 2008, 88).

5. Las imágenes, ilustraciones, fotos, gráficas o cuadros, debe estar identificados de manera precisa y numerados.

a) El manuscrito original debe señalar el lugar de colocación de las imágenes, ilustraciones, fotos, gráficas o cuadros con una inserción textual entre corchetes, ejemplo [Figura 1. Título, comentario o pie].

b) Se debe redactar un listado numerado de imágenes ilustraciones, fotos, gráficas o cuadros en un archivo electrónico independiente, que debe coincidir con las imágenes citadas dentro del texto. En el título, comentario o pie especificar la autoría; si son

1 El uso de corchetes esta permitido si se suprime una o más palabras, indicando con tres puntos suspensivos en su interior [...]. También se usarán corchetes para señalar añadidos o precisiones de parte del investigador. de elaboración propia, o si se trata de un "detalle" o "fragmento". Asegúrese de no condicionar la claridad de un texto a la presencia de una imagen.

6. Enviar cada una de las imágenes, cuadros o gráficas a publicar por separado, en formato.JPG y con resolución de 72dpi. Debe tener 700px de alto. De ninguna forma se aceptarán en otro formato o programa. iiIMPORTANTE!! Es necesario que cuente con la propiedad intelectual de cada imagen o en su caso, con el permiso escrito para publicar dicha imagen, usted firmará una autorización de publicación.

7. DIS publica la modalidad de reseña crítica. Por "crítica" entendemos que la reseña debe ser un comentario referido al contexto académico y cultural en el que se inscribe la obra.

- Sólo se admite UN autor por reseña. Pueden participar estudiantes.

El texto de la reseña crítica incluirá lo siguiente:

- Una presentación breve del contenido de la obra reseñada.

- La relevancia de la obra reseñada y el porqué de la importancia de elaborar la reseña crítica.

- La importancia del tema y la discusión en la que se inscribe, más el enfoque historiográfico.

El contexto del libro reseñado, en función de diversos criterios:

a) En relación con la obra del autor.

b) En relación con el tema.

c) En relación con la problemática (conceptual, argumentativa, referencial, ...)

d) En términos comparativos.

El texto de la reseña crítica irá precedido de la ficha bibliográfica del libro objeto de comentario. Ejemplo de la ficha del libro:

Romero De Terreros, Manuel. Crabados y grabadores de la Nueva España. México: Ediciones Arte Mexicano, 1948, 10. 